УДК 78.01/784+785

\title{
Лю Юйтен
}

\section{ТИПОЛОГИЧЕСКИЕ ЧЕРТЫ КИТАЙСКОЙ КАМЕРНО- ВОКАЛЬНОЙ ЛИРИКИ В СВЕТЕ АКТУАЛЬНЫХ МУЗЫКОВЕДЧЕСКИХ ПОДХОДОВ}

Главной иелью статьи становится определение ведущих принципов музыковедческой синологии в сфере камерной вокальной музыки и обоснование приоритетных жанрово-стилевых признаков камерной вокальной миниатюры в творчестве китайских композиторов. Раскрывается значение песенного жканра в становлении китайской профессиональной композиторской школы и специфического национального (китайского) типа авторского, то есть личностного, музыкального сознания. Устанавливается тот «вертикальный горизонт» (словообраз И. Бродского), который указывает на уровень возникновения художественной «макроконцепции» - необходимого фактора формирования китайской камерно-вокальной академической традиции.

Ключевые слова: национальная традиция, ценностная художественная морфология, историко-культурный диалог, китайское поэтическое слово, китайское мифопоэтическое мышление, китайская музыкальнопоэтическая лирика.

До сегодняшнего дня не утрачивает своего значения изучение многообразия взаимодействия слова и музыки, особенно в контексте вокальной лирики, предусматривающей единство и противопоставление поэтического и музыкально-интонационного рядов [2-4]. Особенно актуальным является компаративное исследование различных культурно-исторических типов художественного объединения поэтического и музыкального начал, из которых наиболее контрастным представляются западноевропейский и восточный, в частности китайский, типы [1; 5].

Следует добавить, что исследование путей формирования, специфических черт и тенденций жанрово-стилевой эволюции китайской камерно-вокальной лирики, в ее опоре на форму музыкально-поэтической миниатюры, является действенным способом обоснования методических, предметно-познавательных принципов музыковедческой синологии, из которых опорными представляются три:

- нахождение в диалоге с широким историко-культурным контекстом и обнаружение особых свойств данного диалога (историкокультурологическая диалогичность); 
- персонализованный подход, позволяющий конституировать важные аспекты процесса понимания - моменты «постижения», открывать их назначение и содержание;

- достижение уровня ценностной морфологии музыкальной культуры - «системы взаимодействующих и взаимодополняющих тем, образов, символов и метафор», благодаря которым, во-первых, «...поэт должен осознавать свое место в мироздании, трактуя «приоритет индивидуального» как «синтез предшествующего опыта поколений»; во-вторых, определяется «некое обобщающее начало» в структуре ведущих художественных образов, обладающих в равной степени эмблематичностью и символичностью, то есть константностью внешних признаков и изменчивостью смыслового содержания, позволяющее создавать «списки понятий» [6, с. 86, 83-84]. Сказанное определяет методическую актуальность и основные задачи данной работы, которая строится в своеобразном дискурсивном диалоге с исследовательской концепцией У Хунюаня.

Вышеуказанные принципы определяют общий теоретический строй труда У Хунюаня, в котором главным предметом выступает так называемая «китайская художественная песня» - условное наименование той жанровой сферы камерной вокальной лирики, которая развивалась в особенно тесном единстве с поэзией, в этом отношении напоминая форму «стихотворения с музыкой», представленную в творчестве западноевропейских композиторов-романтиков. Аллюзии к западной культуре щедро насыщают это исследование, начиная с названия первого подраздела диссертации - «Рождение китайской художественной песни из духа философско-эстетической мысли о музыке древнего Китая» - содержащего аллюзию к наименованию известного труда Ф. Ницше («Рождение трагедии из духа музыки», 1872) и указывающего на тот огромный хронотопический объем культурного диалога, который приходится осваивать и сохранять в художественном сознании в единственно подходящих для этого символических формах.

Китайский музыковед пишет: «Научное описание структуры и свойств образца китайской художественной песни, направленное на установление максимального круга свойственных ему символов, посредством которых осуществляется взаимодействие планов миниатюры и макровосприятия, требует их последовательного раскрытия, обнаружения системы связей между ними, обоснованной разгадки оставшихся в зоне «невидимого» черт макромира. Реализация данной 
исследовательской задачи ведет к тому, что исследование пусть даже самой миниатюрной китайской художественной песни закономерно ведет к возникновению достаточно значительного объема научного текста» [6, с. 188]. Пример аллюзивно-символического мышления самого диссертанта находим в завершении третьего раздела работы, когда читаем следующее: «Сочинение Лу Цзай-и - романтическая песнь о земле, отражающая закономерности бытия. Напластование смыслов отображено в формообразовании. Диадность (двухчастность) композиции соотносится с триадностью (принцип цикличности, символизирующий идею непрерывной повторяемости фаз жизни - смерти - возрождения), и принципом сквозного развития, способствующего раскрытию идеи постоянного обновления мироздания и человеческих чувств» [6, с. 170].

В диссертационном дискурсе предложена очень тонкая двойная аллюзия к «Песне о земле» Г. Малера, а также демонстрируется особая способность параллельного мышления и метонимизации значений способов формообразования, вообще - запечатлевается особое китайское отношение к форме как самодостаточному факту бытия. Как и авторы вокальной лирики, творчество которых он изучает, У Хунюань стремится представить в тексте форму, ожидающую наполнения духом - в полном соответствии с конфуцианской доктриной, утверждающей, что явление предшествует сущности, следовательно, сперва образуются формы, а затем возникает духовное содержание.

Диалогический принцип в единстве с персоналистским подходом продолжает развиваться во втором разделе исследования в связи с необходимостью создания общего социополитического контекста существования китайского композиторского творчества в XX веке, также в связи с углублением сравнительно-типологических оценок феномена «художественной песни» как именно Kunstlied, то есть как явления иноязычной - немецкой - генетики. Сразу отметим, что второй принцип музыковедческой синологии У Хунюаня обстоятельно реализуется во втором и третьем разделах диссертации, тогда как третий, ценностно-морфологический, начинает формироваться в материале третьего раздела и эксплицируется, достигает методической чистоты в четвертом, завершающем и обобщающем, явно концептологическом, что и придает названному принципу методологическую весомость.

У Хунюань неоднократно возвращается к мысли о важности применения к анализу китайской художественной песни способа «глу- 
бокого постижения» музыки, характерного для философско-эстетической мысли Китая, с целью выявления показательных для жанра смыслообразов (и в формулировках задач, и в определении слагаемых методологии и факторов научной новизны во введении, и в дальнейшем ходе работы).

Данный метод остается в каком-то отношении герметично закрытым, поскольку, по словам У Хунюаня, «анализировать музыкальное искусство с помощью логики невозможно», а «логическое не способно охватить необъятное содержание музыки. Необходимо «слушать сердцем», переводить ощущения внутрь души. Душу закрепощают чувства и идеи, разрушают ее чистоту», мало этого - «нужно превзойти сердце и «слушать энергией «ци» [6, с. 20]. Так У Хунюань актуализирует представление древней китайской философии о том, что сердце - орган мышления человека.

Но все-таки есть и ключи к постижению: контекстуальный и текстуально-интенциональный. Первый выражен в призыве «...изучать китайскую культуру как внеевропейскую», что позволит актуализировать «специфический для науки Китая процесс познания - «понимания через сопереживание», для которого «сопереживать» означает постигать объект исследования с позиций культуры, к которой он принадлежит» [6, с. 10]. Китайское поэтическое слово становится проводником в музыкальный микрокосм китайской художественной песни, который обнаруживает самую тесную связь со способами мифопоэтического мышления.

Второй адресован именно целостной и единой мифопоэтике китайской художественной песни, в соответствии с китайской эстетической концепцией восприятия, требующей многократного всматривания «вслушивания» в объект постижения в его нерушимой и имманентной целостности, до тех пор, пока он не становится предметом рефлексивного, но не личностно-судящего, а отождествляемого, сознания, благодаря преодолению различных уровней соответствий - несоответствий между объектом и предметом восприятия.

В соответствии с данным методическим критерием постиженияпонимания уже словесная формула «китайская художественная песня» представляется цельным образом, указывающим на совокупное и исторически выработанное отношение китайских музыкантов к европейской традиции, своеобразным номинативным «якорем» для которого стало немецкое понятие Kunstlied, вернее китайское пред- 
ставление-понятие о немецкой авторской (композиторской) вокальной романтической лирике, заключенное в слове-эмблеме Kunstlied.

Как пишет У Хунюань, появившееся в 20-х годах XX века «понятие «Kunstlied» стало известным в Китае, благодаря Сяо Юмею, который после учебы в Германии в 1920-х годах познакомил китайскую интеллигенцию с его содержанием и с представляющими его классическими художественными образцами...»; «с точки зрения Сяо Юмея, под понятием «художественная песня» следует подразумевать жанр романтической песни не только австро-немецких, но и других европейских композиторов...»; также «из концепции Сяо Юмея следует, что художественная песня и романтическая песня представляют собой синонимические понятия. Для истории жанра китайской художественной песни подобное отождествление и в настоящее время является актуальным» [6, с. 33].

Эти и подобные наблюдения диссертанта позволяют судить о мере условности выделения в качестве первообразца для китайской художественной песни именно немецкой lied, хотя получение многими китайскими музыкантами образования в немецких высших учебных заведениях должно было этому поспособствовать. Но особенно интересно то, что обучавшиеся в Германии китайские композиторы ориентировались в своих стилевых предпочтениях (в период жанрового становления китайской художественной песни) не на творчество современных им немецких мастеров, а на уже ставшие традицией произведения призванных представителей «отзвучавшего» романтизма.

Подобное заимствование с некоторым хронологическим отставанием - характерный симптом, во-первых, явления трансплантации, как достаточно прямого заимствования опыта чужой культуры, по терминологии Д. Лихачева, усматривавшего данное явление в истории русской культуры, но предполагавшего и его более широкое пространственное качество; во-вторых, указание на то, что переносзаимствование не является буквальным, а строится, скорее, мемориально-мнемоническим путем, извлекается из памяти культуры.

Но для китайских композиторов память культуры была прочно связана с древней китайской философией и порожденной ею поэзией, с поэтикой даосских ритуалов и наставлениями конфуцианства, то есть она была своей, иной, не похожей на европейскую. Поэтому, руководствуясь жанровой идеей камерно-вокальной миниатюры, из разновидностей которой наиболее подходящим оказался тип «сти- 
хотворения с музыкой», китайские композиторы формируют собственную модель камерно-вокального произведения, позволяющую воссоздавать «ценностные списки» семантических рядов почвенной глубинной китайской поэзии, мифопоэтически укреплять традиционный этос музыкального творчества.

У Хунюань обнаруживает эти особенности становления и жанрово-стилевой кристаллизации китайской художественной песни путем тщательного перечисления композиторских имен, общежизненной и творческой музыкально-аналитической характеристики многих, ставших значительными, представителей молодой китайской композиторской школы.

Развивая персоналистский подход к социокультурной истории и процессу отбора поэтических текстов для китайской художественной песни, диссертант доказывает известное сближение и даже частичное тождество лирического героя камерно-вокальной музыки и автора, ее создавшего, а в силу значительности содержания, которое оформляло образ мифопоэтического героя, автор представал своего рода героем культуры, достойным особого упоминания и похвалы.

Достижение «непроявленного», Дао - изначального состояния мира, создание иллюзорного образа - то слышимого, то нет, то кажущегося, то реального, особое значение образа тишины как отражения Дао, задача достижения великого звука в беззвучии, обусловливающая стремление к медленному темпу [6, с. 22, 26], идея вечного возвращения (циклического времени), с которой связана перманентная тоска по весне, живущая в сердце китайца даже в самый разгар этого времени года [6, с. 147], запечатление моментов жизни, живущих в сердце, таковы найденные У Хунюанем особые, возможно, главные приметы имманентности семантики и стилевых ориентиров китайской художественной песни, доказывающие ее внутринациональное, хотя и при воздействии внешних культурных стимулов, происхождение.

Есть и другие, музыкально-конкретизированные, обнаруживаемые в суммирующем результате аналитического рассмотрения песенных образцов четвертом разделе: почти полное отсутствие куплетности и повторности, миниатюризация масштабов китайской художественной песни, «приведшая к возникновению абсолютной вокальной миниатюры как одной из внутрижанровых дефиниций китайской художественной песни», обусловленной «преломлением свойств национального художественного мышления, запечатленного в старинных поэтических формах» [6, с. 184]. 
A «согласно Цин Чжу, музыкальное произведение, написанное китайским композитором на китайском языке, независимо от того, какую инонациональную жанрово-стилевую концепцию оно бы ни развивало, является исключительно китайским по своему содержанию и целиком и полностью принадлежащим китайской национальной культуре» [6, с. 185].

Идея уникального совмещения композитора и поэта в одном творческом лице Цин Чжу «как особой разновидности в структуре жанра» [6, с. 65] преобразуется в исследование уникальности таланта, одновременно универсализма интересов Тань Сяо Линя, как одного из любимых учеников П. Хиндемита, индивидуальных свойств «иносказательного стиля» Чень Тянь Хе, экспериментальных авангардных сторон творчества Ло Чжунжуна, композиторских и теоретических музыковедческих достижений Ли Инхая, в смелую сравнительную характеристику замысла произведения Лу Цзай-и оперной концепции Liebestod Рихарда Вагнера [6, с. 166].

В музыкально-аналитическом плане работы выделяется обсуждение:

- особой важности интонемы вопроса в интонационной драматургии китайской художественной песни;

- возможности трактовки восходящей сексты (как большой, так и малой) в качестве интонемы желания/возвращения и темы тоски по родине, завуалированной в поэтическом тексте песни, в связи «с обращением композитора к пентатонике как символу национального музыкального мышления» [6, с. 80-81];

- явного предпочтения двухчастных структур как далекого отголоска дихотомических представлений об устройстве мира;

- предпосылок антологизации китайского музыковедения, посвященного проблеме китайской художественной песни, и развития исполнительских интерпретативных проекций теории данного жанра.

Попытки провести параллели между жанровой формой китайской художественной песни и камерно-вокальным творчеством немецких романтиков как типологически близкими явлениями в наибольшей степени обусловлены тенденцией камерно-вокально творчества, и в его западной, и в его восточной разновидностях, к утверждению личностного аспекта мировосприятия, следовательно, авторского, персонифицированного во всей системе выразительных средств, начала.

Однако это не является достаточным основанием для того, чтобы говорить о единой жанровой модели произведений немецких и 
китайских мастеров музыки и наличии «европейской матрицы» в качестве жанрового архетипа последних (как это делает У Хунюань) тем более, что очевидным предстает выведение формулы уникальности, беспрецедентности жанрово-стилевой парадигмы китайской вокальной лирики, поскольку она имеет своим поэтическим основанием тексты древнекитайских поэтов-философов, создающих особую доктрину миросозерцания и определяющих символические ряды предметных реалий, не имеющие аналогов в западноевропейской поэзии.

Хотя достаточно справедливо и суждение о том, что «роль немецкой Kunstlied в китайской художественной песне находит свое выражение, в частности, в формировании такого стилевого феномена как китайский романтизм ХХ века», но тут же отмечено, что «связи художественной песни с традициями европейского музыкального романтизма не ограничиваются жанрово-стилевыми параллелями с немецкой Kunstlied» [6, с. 54].

В любом случае жанрово-стилевые обобщения относительно природы и своеобразия формы и содержания китайской камерновокальной лирики требуют убедительных аналитических доказательств, выводимых из музыкально-стилистического содержания. Такие аналитико-стилистические верификации обнаруживают некоторые противоречия в имманентной жанровой логике китайской авторской песни.

Так, по своему основному семантическому строю она тяготеет к тишине, красоте молчания, неявному, иллюзорному и т. д. Однако она же обнаруживает «дух революционного романтизма», «радикальность, бурную энергию», мощь «нового музыкального движения» [6, c. 45], «идеологическую окраску» в связи с общественными волнениями [6, с. 51], которые вряд ли осуществимы в созерцательной тишине и медитативном погружении.

Отсюда важность разработки терминологии, используемой для определения внешних и внутренних предпосылок развития китайской художественной песни: внешне-аккультурационных и имманентных стилевых; первые оказываются связанными с проникновением в систему китайского художественно творчества и музыкального образования тенденций европейского искусства; вторые обусловлены тем, насколько востребованы в китайской культурной среде и в каких жанрово-коммуникативных ракурсах музыкальнопоэтические миниатюры, в том числе их песенная форма? 
Можно прийти к выводу, что сегодня понятие «художественная песня» как синонимичное категории «авторская песня» становится более широким и теряющим свою жанровую строгость. Известны сборники китайских музыковедческих материалов и музыкальных опусов - вокальных миниатюр - под общим названием «художественные песни», материалом которых служат не только образцы данного жанра, но и народные, революционные песни, романсы, отрывки из китайских опер (например, составленный Ли Чумином сборник статей, изданный в Шанхае в 2009 году и вокальная антология китайской художественной песни под редакцией Лю Чжинина, Ли Бинсина и Чжу Ланга (Luo Xianjun, Li Binsun, Xu Lang).

Следовательно, активная исследовательская имплементация опыта китайского музыкознания и китайского композиторского творчества («художественной музыки») свидетельствует о необходимости кросс-культурной разработки связей между китайской и европейской композиторскими школами, причем в значительном историческом диапазоне, от китайского средневековья, существенно более раннего, чем западноевропейское, к романтическому европейскому девятнадцатому веку и к XX столетию как особому этапу в развитии китайского композиторского профессионализма...

С музыковедческой позиции - это постижение и представление той трансформации художественного диалога с европейским искусством в солилоквиум национальной традиции, которая обеспечила не только жанровую уникальность формы камерно-вокальной миниатюры в китайской традиции, но и стилевую уникальность авторского композиторско-поэтического претворения основополагающих в художественно-семантическом отношении идей классической китайской философии.

\section{СПИСОК ЛИТЕРАТУРЫ}

1. Антология китайской поэзии. Т. 1 / пер. с кит. [под общ. ред. Го Жо-жо, Н. Т. Федоренко]. - М. : Гослитиздат, 1957. - 423 с.

2. Васина-Гроссман В. А. Музыка и поэтическое слово. [Ч.] 1 : Ритмика / В. Васина-Гроссман. - М. : Музыка, 1972. - 150 с.

3. Васина-Гроссман В. А. Музыка и поэтическое слово. Ч. 2 : Интонация. Ч. 3 : Композиция / В. Васина-Гроссман. - М. : Музыка, 1978.

4. Лобанова О. Ю. Об отражении интонационной структуры стихотворной речи в вокальных произведениях : автореф. дис. ... канд. искусствовед. : спец. 17.00.02 - муз искусство : спец. 10.02.01 - рус. язык / О. Ю. Лобанова ; Гос. консерватория литовской ССР. - Вильнюс, 1986. -24 с. 
5. Лю Бинцян. Музыкально-исторические параллели развития искусства Китая и Европы / Лю Бинцян. - Одесса : Астропринт, 2014. - 440 с.

6. У Хунюань. Китайская художественная песня: история и теория жанра : дис. ... канд. искусств. ; спец. 17.00.03 - музыкальное искусство / У Хунюань. - Харьков, 2016. - 231 с.

Лю Юйтен. Типологічні риси китайської камерно-вокальної лірики у світлі актуальних музикознавчих підходів. Головною метою статті стає визначення провідних принципів музикознавчої синології в сфері камерної вокальної музики і обгрунтування пріоритетних жанрово-стильових ознак камерної вокальної мініатюри у творчості китайських композиторів. Розкривається значення пісенного жанру в становленні китайської професійної композиторської школи і специфічного національного (китайського) типу авторської, тобто особистісної, музичної свідомості. Встановлюється той «вертикальний горизонт» (словообраз І. Бродського), який вказує на рівень виникнення художньої «макроконцепції» - необхідного чинника формування китайської камерно-вокальної академічної традиції.

Ключові слова: національна традиція, ціннісна художня морфологія, історико-культурний діалог, китайське поетичне слово, китайське міфопоетичне мислення, китайська музично-поетична лірика.

Liu Yuthen. Typological features of the Chinese chamber-vocal lyrics in the light of topical music-approaches. The main goal of the article is the definition of the leading principles of musicological synologism in the field of chamber vocal music and the substantiation of priority genre-style features of chamber vocal miniatures in the work of Chinese composers. The significance of the song genre in the formation of the Chinese professional composer school and the specific national (Chinese) type of the author's, that is, the personal, musical consciousness, is revealed. This «vertical horizon» (the Brodsky image-word) is established, which indicates the level of the emergence of artistic «macro-conception» - an indispensable factor in the formation of the Chinese chamber-vocal academic tradition.

Keywords: national tradition, valuable artistic morphology, historical and cultural dialogue, Chinese poetic word, Chinese mythological poetry, Chinese musical poetry lyrics.

Стаття надійшла до редакції 18.05.2016

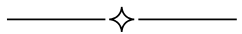

